\title{
EL ADULTOCENTRISMO EN LA EDUCACIÓN MATEMÁTICA INICIAL: DOS DISCURSOS EN CONFLICTO PARA LA CONVIVENCIA DE LOS SABERES MATEMÁTICOS
}

\author{
ADULT-CENTEREDNESS IN EARLY MATHEMATICS EDUCATION: \\ TWO CONFLICTING DISCOURSES FOR THE \\ CO-EXISTENCE OF MATHEMATICAL KNOWLEDGE
}

Milagros Elena Rodriguez ${ }^{1}$

\section{RESUMEN}

El objetivo complejo es analizar el adultocentrismo en la Educación Matemática inicial en dos discursos en conflicto para la convivencia de los saberes matemáticos: los saberes de la cotidianidad del niño(a) y los saberes científicos impuestos en el aula; usamos la deconstrucción rizomática como transmétodo. Enmarcado en la línea de investigación titulada: Educación Matemática Decolonial Transcompleja. En la reconstrucción de la investigación se dan preeminencia al ser humano urgente en la Educación Inicial; cobra urgencia la ruptura del adultocentrismo, escuelacentrismo, docentecentrismo para favorecer el desarrollo del pensamiento metacognitivo de alto nivel y la liberación onto-epistemológica de la matemática en los actores educativos. Los juegos desde su convivencia cultural-comunitaria en el niño y la niña, el respeto a su condición humana y la fe en que todos pueden aprender matemática. Urge des-ligar la formación soslayada del docente hacia un re-ligaje de la ciencia matemática reconociéndose en ella y reconociendo su preeminencia armónica en la creación de la vida y saberes.

Palabras-Clave: Adultocentrismo; Educación Matemática; Saberes.

\begin{abstract}
This study aims to analyzing adult-centeredness in early mathematics education in two conflicting discourses for the coexistence of mathematical knowledge: the child's everyday knowledge and the scientific knowledge imposed in the classroom. We use rhizomatic deconstruction as a research method, which is part of the research line entitled Transcomplex Decolonial Mathematical Education. In the reconstruction of the research, human beings are given preeminence in early childhood education; the rupture of adult-centeredness, school centrism and teacher-centric philosophies is urgently needed to favor the development of high-level metacognitive thinking and the onto-epistemological release of mathematics in educational actors.
\end{abstract}

Keywords: Adult-centeredness; Mathematical Education; Knowledge.

\footnotetext{
${ }^{1}$ Atualmente é Docente Investigadora titular a dedicación exclusiva del Departamento de Matemáticas, Docente de Postgrado en Educación, Postgrado en Administración y Postgrado en Biología de la UDO. PhD. en Ciencias de la Educación, Doctora en Patrimonio Cultural, Doctora en Innovaciones Educativas, Magister Scientiaurum en Matemáticas, Licenciada en Matemática. e-mail: melenamate@ hotmail.com
} 
Cuando el poder se transita a los estudiantes se puede tener una Educación Matemática exitosa; pero que cuando su ejercicio se hace negativamente donde el docente no toma en cuenta el conocimiento previo del estudiante, su contexto entre otras; y no hace circular el poder en el aula, ejerciendo una relación epistemológica sujeto-objeto, se desencadenan efectos adversos a la verdadera finalidad que debe tener la Educación Matemática como: violencia, discriminación, aislamiento, rechazo y pasividad frente a la ciencia matemática, que no contribuyen al desarrollo humano del estudiante (RODRÍGUEZ, 2013, p.7). Entre esos abusos de poder conseguimos al adultocentrismo.

\section{RIZOMA INICIO. CONCEPCIONES DEL ADULTOCENTRISMO COMO FALSA FILOSOFÍA SOSLAYADORA}

La realidad que marca el epígrafe de la Educación Matemática da cuenta de estudios que describen y son un grito en contra del abuso de poder a los estudiantes en la enseñanza. Los sistemas de educación mundialmente son reproducciones de poder, soslayación o liberación; ellos no pueden permanecer fuera del ejercicio de poder; no son neutros; así como tampoco las políticas educativas, los currículos y actores educativos. Por mucho tiempo la escuela, denominada acá a toda institución educativa, es portadora de dominación y encuadramiento mental, emparejamiento en el deber ser de lo que se cree debe funcionar el ser humano; así todo sistema de educación como lo constituye la escuela es una forma política de mantener o de modificar la adecuación de los discursos, con los saberes y los poderes que implican (FOUCAULT, 1990).

¿Qué sucede en los niños y niñas en los niveles iniciales de educación? Ellos heredan el acervo cultural, las normas y valores, y junto con ello, la naturalización de sus condiciones respecto al mundo, y de las relaciones que en él instituye, es decir, los niños y niñas se identifican con los significados brindados por adultos y los interioriza; lo instituyen (SERRANO-MARTÍNEZ, 2016). Todo ello, para bien o mal en el infante; para su superación mental y crecimiento; o para su amaestramiento.

La palabra amaestramiento puede sonar fuerte en tanto los animales les suceden; pero las narrativas que más adelante se instituyen en la colonialidad del saber, ser, poder, soñar y hacer da cuenta de ello. Y de cómo se constituye un ser humano modelo a como conviene comportarse para un proyecto hegemónico y de lo que se espera de ese ser productivo de un 


\section{Revista \\ Debates Insubmissos}

sistema e institutico para continuar la perpetuación con instrumentos nuevos de soslayación. Volvemos pronto sobre la palabra en cuestión.

Así mismo, queremos definir la colonialidad partiendo del sistema dominante luego de la invasión al Sur por Europa; en 1492, tiene una particularidad esencial que es el pensamiento abismal, es lo que caracteriza la racionalidad eurocéntrica; esto es la creación de abismos sobre el pensamiento, sobre la vida humana y natural; es una condición de explotación y sumisión, una metáfora de Boaventura de Sousa Santos, para aplicar la seguridad de la globalización, el hiperconsumo y la homogenización y así fragmentar el mundo en una geodesia hipermoderna que exterioriza en una sociedad hegemónica desarrollada y las otras sociedades coloniales (SANTOS, 2014).

Mientras que, la modernidad para Dussel (2000), es la instrumentalización de la conquista, de la imposición cultural y de la superioridad de una civilización sobre otras; lo que en apariencia parece un asunto racional en civilizar al salvaje revela la sofisticación del dominio, en este caso de Europa hacia América, y más tarde lo sería Estados Unidos y el resto del mundo. La Modernidad acota el pensador: "es [la] justificación de una praxis irracional de violencia” (DUSSEL, 2000, p.48), que empañó al mismo tiempo, las intenciones elevadas que pudo tener en algún momento este proceso a lo interno de Europa, es decir fuera de la vinculación con América.

Desde luego, la colonialidad va más allá del colonialismo; pues es la soslayación impuesta que luego de la liberación de los impostores de Occidente queda como mecanismo de soslayación. Por su parte, los aportes de Michel Foucault en colonialismo y en colonialidad son estudiados, y aunque no son objeto de disertación acá se hace referencia a ellos: Michel Foucault y la colonialidad del poder (CASTRO-GÓMEZ, 2007) y Michel Foucault: colonialismo y geopolítica (CARTRO-GÓMEZ, 2010). El genealogista aporta con sus indagaciones a la presente indagación.

Profundizando, podemos definir el amaestramiento, de acuerdo con el genealogista Michel Foucault, este pertenece al poder disciplinario, entre los que se ubican así como las técnicas de amaestramiento; los ordenamientos de dominación, los procederes de obtener la 
obediencia; y la educación es un espacio por excelencia para tales ejecuciones; para que se lleven cabo (FOUCAULT, 2008). ¿A que creen que se deba que un niño y niña que no nace con predisposiciones, que se va permeando del ambiente, de los otros seres se crea capaz de aprender determinados contenidos o no?, ¿de dónde surgen sus predisposiciones, sus males de la psique, sus minimizaciones? Adelante que la escuela, los docentes tenemos una gran carga en esas minimizaciones que irrespetan la condición humana del niño y de la niña. Podemos decir con firmeza, que "una de las problemáticas que más fuertemente afectan a la niñez, deviene de la relación misma que establece con la adultez" (LAY-LISBOA \& MONTAÑÉS, 2017, p.326).

¿Qué sucede en la escuela? La escuela, desde dispositivos que sistematizan una representación patriarcal (MARTÍNEZ, 2016), que desde luego es arbitraria e imaginaria y perpetuadora en el tiempo, sigue "reproduciendo los presupuestos de relaciones patriarcales que se han venido pronunciando en hombre-mujer y en adulto/a-niño/a) donde los nuevos miembros incorporan la doble arbitrariedad en la relación docente-estudiante" (LAYLISBOA; MONTAÑÉS, 2017, p.326). Esto es sigue el docente perpetuando el poder patriarcal en la escuela.

Hacemos énfasis que el patriarcado puede definirse como un sistema de relaciones sociales sexo-políticas-económicas-educativas basadas en diferentes instituciones públicas y privadas y en la solidaridad instaurada por los hombres, por superioridad impuesta sobre las mujeres, hombres como grupo social y en forma individual y colectiva, que oprimen a las mujeres también en forma individual y colectiva y se apropian de su fuerza productiva y reproductiva, de sus cuerpos y sus productos, ya sea con medios pacíficos o mediante el uso de la violencia, o resultado de dominación (FONTENLA, 2008).

Si bien la categoría "adultocentrismo no ha sido ampliamente teorizada, es clave para la construcción de un marco teórico significativo para la comprensión de la diferencia generacional, inscrita en relaciones de poder en discursos cotidianos, institucionales" (VÁSQUEZ, 2013, p.218) y para luego extrapolar la relación docente-niña(o) en la Educación Matemática inicial. No haremos un tratado del adultocentrismo; pero si daremos ejes 
constitutivos del adultocentrismo como política soslayadora, como filosofía alienante al ser humano.

Michel Foucault, uno de los genealogistas más importantes marca pautas para la comprensión del adultocentrismo, como consecuencia de la modernidad como proyecto de dominación.

Que hombres dominen a otros hombres, y es así como nace la diferenciación de los valores; que unas clases dominen a otras, y es así como nace la idea de la libertad; que hombres se apropien de las cosas que necesiten para vivir, que les impongan una duración que no tienen, o que las asimilen por la fuerza -y tiene lugar el nacimiento de la lógica (FOUCAULT, 1992, p.15).

Allí nacen distintos dispositivos de soslayación que han permeado la educación, como proceso adoctrinador por excelencia. En las instituciones educativas se permean discursos en los adultos dignos de ser estudiados y pensados como consecuentes de una regularización del conocimiento y el hacer y pensar del discente; la producción del discurso está a la vez "controlada, seleccionada y redistribuida por cierto número de procedimientos que tienen por función conjurar sus poderes y peligros, dominar el acontecimiento aleatorio y esquivar su pesada y temible materialidad" (FOUCAULT, 1999, p.14). ¿Qué procedimientos constituyen el discurso?, ¿continua la escuela con el desarrollo del dialogo dialógico-dialéctico que trae el niño y niña del hogar?

Para ello, definamos que es el dialogo dialógico-dialéctico. El dialogo dialéctico está orientado a la "discriminación entre verdad y error mediante el pensamiento" (PANIKKAR, 1999, p.27), este tipo de diálogo parte de la hipótesis de que los participantes cooperan en una racionalidad, como el principio de no contradicción, y de ese modo pueden someter sus perspectivas a la audiencia de la razón; ello se pretende aplicar en los conceptos de la matemática, por ejemplo y se conoce de los diálogos de Platón, Sócrates entre otros. Panikkar (2003) piensa que el diálogo dialéctico, si bien tiene su lugar en ciertos ámbitos de la vida humana, es insuficiente para asumir los retos de la interculturalidad; así en la educación la comunicación es posible y debe ocurrir en un nivel diferente al de la dialéctica; pero desde luego no divorciada de ella. Por ello

El diálogo dialógico no tiene ni a la victoria en el contexto de las ideas ni a un acuerdo que suprima una auténtica diversidad de opiniones. El diálogo dialógico 
busca, si acaso, expandir el campo de comprensión, con la profundización por parte de cada interlocutor de su propio campo de comprensión y la apertura de un posible lugar para lo (¿todavía?) no comprendido (PANIKKAR, 2003, p.67).

¿Los adultos en la Educación Inicial permean sus discursos en estas direcciones del dialogo dialógico-dialéctico? Como podemos ver, el diálogo dialéctico es sobre objetos, sobre sus doctrinas, temas o problemas que se tratan en la ciencia; pero el diálogo dialógico es entre sujetos, entre docentes y discentes, porque el dialogo entre ellos en la Educación Matemática, por ejemplo, es sobre ellos mismos y de ese modo consiguen entrar cada uno en el universo cultural del otro; para ello e imperativo considerar la cultura, cotidianidad de la matemática; cuestión posible en la decolonialidad planetaria donde la Educación Matemática y la matemática toma en cuenta la complejidad y toda extensión de los aportes matemáticos; inclusivos del Sur y de los países soslayados.

Es más, el diálogo dialógico asume un radical dinamismo de la realidad, esto es, que "la realidad no es dada de una vez para siempre, sino es real justamente por el hecho de que está continuamente creándose a sí misma y no simplemente desarrollándose a partir de premisas y puntos de partida preexistentes” (PANIKKAR, 1999, p.38) ¿Cómo es posible este encuentro dialógico-dialéctico en la Educación Matemática?

Nos hemos adentrado entonces en reconocer que nos interesa esa relación entre adultocentrismo y Educación Matemática en los niveles iniciales educativos, la crisis que se permea en dicha educación con el patriarcado particular del docente en el niño y niña. Desde luego, en el rizoma que deviene explicitaremos la problemática entre adulto docente y niño y niña en dicha educación. Nos permearemos de las bonanzas de la transmetodología que explicaremos en lo que sigue para clarificar objetivo complejo, transmétodo. Y continuaremos con las inserciones en las concepciones del adultocentrismo.

\section{RIZOMA TRANSMETÓDICO. LA TRANSMETODOLOGÍA DE LA INVESTIGACIÓN}

Cuando el arte de pensar estas preguntas en la indagación que hemos venido atesorando en el rizoma anterior, vamos a discernir una palabra que sin duda marca la 
distinción en las investigaciones modernistas clasificadoras del deber ser Occidental; la división: introducción, desarrollo, resultados, conclusiones. Se trata de la palabra rizoma, que habla de la compleja relación en toda la investigación.

Heredamos de la Biología la palabra rizoma, que acá se rescata para marcar la distinción más allá de ese síndrome de división soslayador de las indagaciones; el rizoma indica que vamos más allá, que no hay centros en el constructor discursivo; donde desde luego vamos más allá de cumplir con un objetivo que denominamos complejo; son rizomáticas en el sentido de que el rizoma se usa de manera envolvente en los subtítulos de la presente investigación (RODRÍGUEZ, 2020a).

Es así como, el rizoma no "empieza ni acaba, siempre está en el medio, entre las cosas, inter-ser, intermezzo (...) el árbol es filiación, pero el rizoma tiene como tejido (...) En esta conjunción hay fuerza suficiente para sacudir y desenraizar el verbo ser" (DELEUZE; GUATTARI, 1980, p. 20). Se usa por primera vez en la investigación de Rodríguez (2017) la palabra rizoma para estructuras de investigaciones doctorales. Es el rompimiento con la tradicionalidad modernista denotada en las estructuras de las investigaciones cualitativas o cuantitativas, como capítulos.

Es así como, esta indagación va más allá de las líneas divisorias reiterativas en la tradicionalidad que son impuestas a muchos investigadores en revistas internacionales; en construcciones en las universidades: introducción, metodología, resultados y conclusiones (IMRC), va más allá pero las contiene y las complejiza en un estadio de pensamiento donde concluyendo está introduciendo investigaciones y los resultados no son las perennes verdades que se ha creído la ciencia que ha conseguido e impuesto: como por ejemplo la división irrisoria de las matemáticas escolares y no escolares (RODRÍGUEZ, 2020a).

La ciencia occidental ha erigido las instituciones que educan al individuo que produce y reproduce el conocimiento, su conocimiento; el Occidental el que se considera válido; hay que reconocer que la educación es una repetidora del conocer, una mecanicista del pensar; sin mayores razonamientos que permitan discernir la soslayación que en plena globalización se sigue imponiendo (HIRA, 2016). El pensamiento occidental ha provocado la perlesía del 


\section{Revista \\ Debates Insubmissos}

pensamiento, que duda de sus capacidades de dar sentido práctico y ético a la acción, termina "traduciéndose en un individualismo auto absorbente, que disuelve los vínculos y lazos personales y sociales imposibilitando un orden político capaz de construir una voluntad general en relación al bien común" (GONZÁLEZ, 2017, p,14).

En esta investigación bajo la transmodernidad como objetivo complejo analizamos el adultocentrismo en la Educación Matemática inicial en dos discursos en conflicto para la convivencia de los saberes matemáticos: los saberes de la cotidianidad del niño(a) y los saberes científicos impuestos en el aula; usamos la deconstrucción rizomática como transmétodo. Todo enmarcado en la línea de investigación titulada: Educación Matemática Decolonial Transcompleja. Iremos conceptualizando todos los términos; lo hacemos a la manera compleja y rizomática diferente a las indagaciones enmarcadas en el proyecto de la modernidad.

La Educación Matemática Decolonial Transcompleja como constructo y línea de investigación nos permite asumirnos como sujetos históricos y políticos que dan sentido a su “existencia al romper su sujeción ideológica a los marcos epistémicos, culturales, axiológicos y ontológicos sobre los que se erigió e instituye la actual matriz de dominación neocolonial de la enseñanza de la matemática modernista" (RODRÍGUEZ, 2020a, p.1). Se trata de una educación liberadora de la ciencia legado de la humanidad y del ser humano soslayado; es un proceso autónomo, propio, hermoso, vivo, desprovisto de falsas creencias y actitudes, lleno de un crecimiento espiritual con la ecosofía conformada por la ecología social, espiritual y ambiental, que atienden el difícil arte de habitar en el planeta. En ese aporte al mundo de una Educación Matemática otra se enmarca esta indagación.

La educación liberadora, en el sentido de Paulo Freire, lo avala los estudiosos de la complejidad; se trata de ejemplificar esa responsabilidad ética, profundamente política ante una acción cultural concientizada en las comunidades, empoderando al ser como responsable de la transformación de su realidad, como antropolítica, la política del ser humano, deberá desarrollar la conciencia política, la perspectiva política, reconociendo y respetando lo que, en ellas, escapa a la política (MORÍN; KERN, 2006). 


\section{Debates Insubmissos}

Revista

En la Educación Matemática Decolonial Transcompleja el sentido liberador se impone ante la actitud concientizada de los docentes, aquellos que "nunca podrá callar ante las cuestiones sociales; no puede lavarse las manos en lo que respecta a esos problemas" (FREIRE; SHOR, 1986, p. 265). Esto lo veremos en adelante respecto al problema del adultocentrismo en la Educación Matemática tradicional,

¿Qué finalidad cumple un transmétodo?, ¿Por qué más allá de los reduccionistas métodos modernistas? buscan involucrarse en procesos develadores encubiertos en discursos, prácticas, acciones y discursos impresos, para con esto descomponerlos, desarticularlos y religarlos con un sentido otro en la temporalidad que nos ocupa, desde una visión de hologramática, del todo y sus partes, de las partes y el todos en un mecanismo permanente de bucle recursivo (MORÍN, 2005).

Por otro lado, la deconstrucción rizomática como transmétodo de indagación "es libre al máximo, anti-dogmática, no tiene ninguna transmetodología fija, su objetivo es debilitar el pensamiento filosófico occidental, destruir las concepciones colonizantes en todas sus formas y significados" (RODRÍGUEZ, 2019a, p.43). Por ello, vamos fuera de las fronteras disciplinarias de la Educación Matemática, dejando el yugo de la soslayación modernista bajo el pensar transcomplejo para estudiar las tecnologías del yo en la Educación Matemática.

Es considerado la deconstrucción rizomática un transmétodo que desarrolla y clama un “proceso descolonizador” (RODRÍGUEZ, 2019a, p.54), que lleva a los sujetos, incluyendo al sujeto investigador a convergen en una Educación Matemática desde la cotidianidad; es así como "las enseñanzas sobre la vida cotidiana se organizaban alrededor del cuidado de sí con el fin de ayudar a cada miembro del grupo en la obra mutua de salvación" (FOUCAULT, 2008, p.53).

En la presente indagación se hace "desenmascaramiento del pensamiento occidental, de la modernidad, los ideales tradicionales impuestos de la educación y sus representaciones sociales” (RODRÍGUEZ, 2020b, p.7) en tanto la enseñanza de la matemática, la enseñanza, el adultocentrismo y otras categorías constitutivas de la indagación. Con la deconstrucción la autora estará en un "ir y venir que va a la criticidad; pero también a la reconstrucción" 
(RODRÍGUEZ, 2020b, p.9) del adultocentrismo, para ejemplificar la enseñanza de la matemática a favor del ser humano, de su vida, re-civilización y el respeto a la condición humana. Categorías que desmitificaremos prontamente. Le solicitamos al lector advertir que la esencia rizomática de la investigación no es lineal y que las categorías se redefinen en todos los rizomas; así como se vuelve a la crisis y a la reconstrucción; y al final que so aperturas de regresan a convergencias de indagaciones por hacer en la mencionada línea de investigación.

En lo que sigue seguimos marcando la crisis a que confluimos en el análisis y lo haremos desde el adultocentrismo en la Educación Matemática inicial donde visionamos dos discursos en conflicto para la convivencia de los saberes matemáticos.

\section{RIZOMA CRISIS. EL ADULTOCENTRISMO EN LA EDUCACIÓN MATEMÁTICA INICIAL: DOS DISCURSOS EN CONFLICTO PARA LA CONVIVENCIA DE LOS SABERES MATEMÁTICOS}

Queremos precisar mesetas deconstructivas del binomio adultocentrismo-educación matemática inicial que darán cuenta parte de la crisis colonial de la enseñanza de la matemática. ¿Qué que convivencia de saberes matemáticos hablamos? Nos referimos a las males denominas matemáticas científicas o escolares y las no científicas o soterradas o no escolares. Nos explicaremos volviendo a los conocimientos matemáticos de los niños y niñas ante de llegar a la escuela, a la denominada Educación Inicial en Venezuela, los primeros niveles educativos escolares.

El niño desde su hogar a parte de sus propios regulativos valores intrincados de conformación matemática de su cuerpo, su ritmo, valores como colesterol, hemoglobina; ritmos cardiacos; procesos neuronales altamente geométricos fractálicos. A parte de ello, y con ello el niño reconoce con sus juegos procesos de clasificación, de seriación. El conoce del número, de las reglas de juegos; desde luego conoce procesos serios a través de sus propios juegos que madurando en la edad va comprendiendo con nociones de matemática desde la concreción. Hemos de denotar que el binomio concreción-abstracción no están separados; el llegará paulatinamente a la abstracción pero desde la concreción. 


\section{Revista \\ Debates Insubmissos}

Por ejemplo, del número el símbolo como tal de cualquier número natural es una abstracción más la representación del número en sus juegos es una concreción. ¿Qué sucede en los procesos mentales de la niña y del niño en el contacto con el docente en sus primeros niveles? El docente impone la abstracción del número como proceso continuo de repetición y lo relaciona el docente con sus juegos. No con los juegos de los niños; estos comienzan a sentirse enajenados del hogar y de la escuela; viven una doble fractura de seriedad impuesta fuera de su seriedad que son sus juegos. Doble imposición porque el docente le impone su clase fuera de sus procesos dialógicos-dialécticos; le es castigado con un no está bien, esta malo no sirve; cuestión que el niño y niña no conoce en sus juegos; es doble porque al llegar a su hogar a la hora de hacer las asignaciones pendientes de la educación inicial muchas veces los padres y representantes le imponen la repetición de las tareas aisladas de sus vidas.

En esa escuela adultocentrica del niño y de la niña

Las generaciones adultas transmiten a las generaciones más jóvenes, su cultura y su tradición, al objeto de garantizar la continuidad del grupo y su ideología. La niñez hereda el acervo cultural, las normas y valores, y junto con ello, la naturalización de sus condiciones respecto al mundo, y de las relaciones que en él establece" (LAYLISBOA; MONTAÑÉS, 2017, p. 324).

En este caso, en la enseñanza de la matemática el niño hereda la concepción repetitiva de la matemática, difícil, imposible de alcanzar; hereda el castigo en que si no repite tal cual se le adoctrina está mal y con ello el castigo de que no sirve para la matemática; pero también heredada la creencia de que la matemática es para unos pocos llamados inteligente; en el que él posiblemente no se encuentra. Hereda una matemática alejada de sus vidas.

En esa herencia difícil e inalcanzable de la matemática, en la mayoría de los casos el niño y niña no comprende porque no comprende los conceptos; ¿Qué le ocurre con la matemática? Al preguntar se le responde repitiendo lo enajenado de su vida que ya le dijeron, la manera repetitiva como el docente le explicó. Y con ello comienza una larga historia de predisposición, rechazo, creencias y alejamiento de la matemática que él conocía pero que se le impuso como monstruo en el aula; el adulto el que perpetuó el castigo con la matemática como excusa. Que así me enseñaron así y así yo enseño afirma el docente; estas historias de vidas contadas por la autora son más comunes de lo que tomamos conciencia en el aula. Así 


\section{Revista \\ Debates Insubmissos}

se perpetúa la matemática y su enseñanza. Es así como, ese "complejo de saberes, normas y prácticas de exclusión en base a la diferencia generacional, le denominamos adultocentrismo" (VÁSQUEZ, 2013, 218), esta vez impuesto en la Educación Matemática inicial.

¿Consecuencias en la psique del niño y de la niña de la práctica descrita anteriormente? La matemática en el ser humano puede permitir dirigir su intelecto, desarrollar sus procesos mentales, la toma de decisiones y el ser y estar en el mundo; es de tan delicado cuidado la oportuna enseñanza de la matemática que "el que no posee una educación matemática se halla privado de algo que es esencial al hombre" (PÉREZ, 1980, p.42). Es que se han configurado adultocentrismo desde los saberes matemáticos mal denominados científicos (VÁSQUEZ, 2013), desmitificando los saberes del niño y de la niña, de sus juegos. Se omite la condición humana y la forma como el niño construye y asume el conocer.

Es así como, en la crisis de la enseñanza de la matemática, su colonialidad impuesta hasta hoy con nuevos artefactos de soslayación, con sus excepciones maravillosas de grandes maestros que despiertan el amor por la ciencia, los avances en tal materia; en realidad en un buen número, "la matemática tradicional, o más bien, la metodología tradicional de enseñanza de las matemáticas, desarrolla la pasividad, la obediencia” (PÉREZ, 1980, p.42). Esa obediencia es la que el adulto docente adquirió del círculo interminable de la soslayación.

Ese adultocentrismo viola en si la condición misma y esencia de lo que es la matemática, él ha sido capacitado en competencias de que la matemática es una ciencia para resolver problemas con fórmulas, símbolos y algoritmos. Desconoce, o pretende ignorar los procesos de pensamiento metacognitivos de alto nivel que sólo se desarrollan a través de la matemática; desvirtúa la cotidianidad de la vida en marcas matemáticas de alto nivel, desvirtúa la esencia de historia y filosofía; marca definitivamente la matemática como una ciencia academicista; siendo la vida matemáticamente hablando en todas partes: en el hábitat popular, en la creación del cuerpo, en la naturaleza, en los planetas y en el Universo mismo Dios creo la vida matemáticamente en siete (7) días desde el génesis.

¿De dónde proviene esa imposición del adulto en la enseñanza de la matemática? El adulto fue educado de la misma manera, y es uno de los remanentes sobrevivientes en su 


\section{Revista \\ Debates Insubmissos}

profesión como docente o matemático; que son sólo unos pocos que llegan a ese escalafón. Él deviene de una matemática colonial, usada como poder de soslayación en su vida; un arma secreta de la modernidad (SKOVSMOSE, 2012); cuando hasta las matemáticas les coloca apellido: las matemáticas occidentales. Ignora el adulto las matemáticas de las civilizaciones soslayadas; las matemáticas del Sur, del avance de las civilizaciones. Desconoce los procesos de creación de grandes matemáticos y su manera de concebir la ciencia. Así convino al proyecto modernista la soslayación y obediencia.

El adultocentrismo marca una predisposición en el tema de la evaluación en la matemática; castiga el error cuando se sabe que se puede aprender del error; y que en el caso de los niñas y niñas la evaluación va en factores complejos y pautas de construcción y comprensión de acuerdo con sus procesos dialógicos que son afectivos en primer lugar. En la enseñanza de la matemática con "el cúmulo de cosas que se les impone, no se les deja a los estudiantes el tiempo de pensar. Y aquel que se atreve a hacerlo corre el riesgo de ser sancionado, porque no repite exactamente lo que le transmitieron" (PÉREZ, 1980, p.45). Esa represión es urgente de desmitificar de contemplar como un atentado a su condición humana.

El adultocentrismo es un tema aún por desentrañar en la educación, en el hogar; un asunto es educar: despertar interés, pasión, luz en el camino; y otra cosa es adoctrinar, imponer, soslayar. Para estudiar el adultocentrismo debemos trasladarnos al análisis de la colonialidad y que esta pasa por la problematización del ser (VÁSQUEZ, 2013). No se niega jamás el carácter de educador del adulto, de guía no de opresión. ¿Cómo llego a ser colonizado el ser del docente, el adulto? es una tarea del mismo docente por desmitificar.

Es que ha venido ocurriendo, que el "adultocéntrico es parte del imaginario colonial, lo decimos en tanto contribuye a develar que "la madurez" o "razón" del "sujeto universal" está fundada también sobre una diferencia generacional (VÁSQUEZ, 2013, p.226). Esto hace que la mirada de niños, niñas y jóvenes no sea tomada en cuenta por el adulto; pues generacionalmente el adulto tiene la verdad e impone su razón. En el caso de la matemática muchos docentes desmitifican lo que el discente descubre en las tecnologías que pudieran aprovecharlo para la enseñanza de la matemática; ir a su mundo para ganárselo y motivarlo al 


\section{Revista
Debates Insubmissos}

aprendizaje. El docente parece un objeto inamovible que impone el estudiante acuda a él para recibir las sabidurías. Ellos están muy lejos del proceso de educar.

La escuela, debe ser pensada y analizada como el espacio para la formacióndominación del alma moderna, niño, niña y jóvenes que se le impone la forma modernacolonial de ser, saber, poder y estar, dicho establecimiento es una institución ideada adultocéntricamente (FOUCAULT, 2002). No debe confundirse la crítica al adultocentrismo con la posibilidad política que debe tener el adulto de guiar, supervisar, con tal que no se convierta en coacción. Lo que pasa en la Educación Matemática, en tanto atentado a los conocimientos matemáticos del estudiante y su condición humana.

El adultocentrismo puede ser entendido como una relación de poder asimétrica entre los adultos los niños, niñas y adolescentes. En los países modernistas-coloniales, existe una matriz socio-cultural adultocéntrica que toma como punto de referencia la posición del adulto, en función de lo que debe hacerse y lo que es considerando valioso en la sociedad: madurez, responsabilidad, integración al consumo, a la producción, reproducción de la familia y participación política en las instancias institucionales como la escuela (DUARTE, 2012). Es así como, lo que conoce el discente de la matemática es desvalorizado y no llevado al aula; entendemos este "adultocentrismo una discriminación etaria que tiene su base en presupuestos biológico-evolutivos, los que generan una equivalencia de sentido entre niño, inmadurez e irracionalidad" (FIGUEROA-GRENETT, 2016, p.120).

El agotamiento del adultocentrismo y su dominio en la Educación Matemática crea nociones que producen dominio: autoritarismo, desmitificación de la inteligencia y el poder aprender matemática en el estudiante, estigmatización en tanto se práctica una exclusión antidemocrática en el aula, entre otras. Todo ello incita a una ruptura con el adultocentrismo y sus consecuencias; para con ello propender una matemática inclusiva, decolonial, compleja y transdisciplinar que sea profundamente dialógica - dialéctica. En eso vamos al siguiente rizoma para reconstruir la Educación Matemática inicial desde la ruptura del adultocentrismo ateniente a la línea de investigación: Educación Matemática Decolonial transcompleja. Que ya fue definida anteriormente 


\section{RIZOMA LIBERACIÓN. LA EDUCACIÓN MATEMÁTICA INICIAL COMO PREEMINENCIA EN EL SER HUMANO: UNA RECONSTRUCCIÓN URGENTE}

Queremos clarificar que la línea de investigación Educación Matemática Decolonial transcompleja "comienza a descentrar el oscurantismo que aún tiene vedados a incluso transparadigmas como la transcomplejidad del que muchos investigadores pretenden realizaciones plenas en rezagos modernistas-postmodernistas" (RODRÍGUEZ, 2020c, p.126). Intenta mostrar en primera instancia que los estudios complejos y transdisciplinarios; que son complejos desde luego, deben enmarcarse en la liberación ontoepiestemológica de la Educación Matemática; esto es en la decolonialidad planetaria. No toda transdisciplinariedad es decolonial. Los estudios transcomplejos no pueden estar enmarcados en la postmodernidad; que siendo el cono de la modernidad es colonial (DUSSEL, 1992).

Es de clarificar que en el plano de la decolonialidad planetaria, "el pensamiento decolonial planetario se diferencia de la teoría poscolonial o de los estudios poscoloniales en que la genealogía de estos se localiza en el postestructuralismo francés más que en la densa historia del pensamiento planetario decolonial" (MIGNOLO, 2007, p. 27). Por ello, veremos más adelante que el transmétodo en la investigación: la deconstrucción rizomática como transmétodo tiene premisa del pensamiento decolonial planetario; más allá del postestructuralismo francés a la que el autor en cuestión hace referencia.

Pero hacemos una aclaratoria, que la decolonialidad planetaria no intenta dar un barrido a los aportes de Occidente para privilegiar al Sur; justo su inclusión no pone superioridades y entonces por ello podemos desconocer "la histórica influencia intelectual de Occidente, y menos los aportes para nuestros propios procesos de descolonización de las críticas a la modernidad como las de Foucault, cuyo locus de enunciación es sin duda occidental” (BELTRAN, 2019, p.78).

De esta manera: Educación Matemática-decolonialidad planetaria-transcomplejidad es la tríada en consonancia para entre otras acciones liberadora ocurra la ruptura del adultocentrismo. Es la ciencia matemática patrimonio de la humanidad a la que todos podemos aprender, con mente, cuerpo y corazón (RODRÍGUEZ, 2020c), su educación la 
convenimos liberar; debemos desoccidentalizar las ciencias de la educación; esto es desligarlas del ejercicio de superioridad, reduccionismo e imposición de Occidente y "develar la doctrinalidad de la educación y la formación, el proceso que oculta la pedagogía en su propuesta de la noción de formación, así como la contradicción entre formación y emancipación. La doctrinalidad es la cara oculta de la formación" (ORTIZ; ARIAS; PEDROZO, 2018, p.1).

Esa doctrinalidad la hemos develado en esta investigación con el adultocentrismo. La misión antropolítica de dicha educación que nos convoca debe ir a lo que esta categoría compone en la esencia del servicio al ser humano; en este caso al niño y la niña en la educación inicial ilusionado por ser feliz, jugar en su amor por el compartir y aventurarse en el conocer; esa esencia afectiva de ser niño y niña debe ser explorado en la escuela; el docente debe conocer y se capaz de desarrollar

Una política de la condición humana que se inscriba de forma natural en un movimiento histórico global en el que la política, al dejar de limitarse al gobierno y al ciudadano, tiende a coincidir con el destino del ser humano, no para engullirlo. El destino del hombre no debe reducirse a la política, es la política la que debe subordinarse al destino de lo humano" (FONTALVO, 2011, p.49).

Esa política del ser humano que se conjuga con las políticas educativas atiende a ese ser humano estudiante como el tesoro más preciado desde el cual la humanidad realizará sus mejores conquistas. Para ello, urgente, no bastan decretos. El docente debe des-ligarse de las falsas sumisiones en el cual él ha sido víctima como esencia de la transmodernidad y misión en la decolonialidad planetaria (RODRÍGUEZ, 2019b); ¿de qué debemos des-ligarnos? Desligarnos de la falsa idea que los conocimientos científicos son los que provienen de las ciencias legalizados en Occidente, que los cotidianos no son científicos. Des-ligarnos de la inhumana consideración a la condición humana del ser que soslaya; des-ligarnos del reduccionismo, de las parcelas disciplinarias que tanto daño en su incomunicación han parcelado la formación del ciudadano en la educación (RODRÍGUEZ, 2020c). Des-ligarse el adulto docente y todo aquel que influya en la educación del niño de su autoritarismo y desconocimiento petulante de lo que es la matemática. 
¿Por qué se dice petulante? Porque el docente porta la matemática y su forma inhumana de llevarla a la educación inicial como arma mortal para soslayar la ciencia ante la vida del discente y con ello al niño y niña, la presenta orgullosamente como el único conocedor de ella, cuando realmente ignora que es la matemática, ¿cómo re-conocerse en ella?, ¿cómo re-inventarse en las historias de los creadores de la matemática?; pero también como humanizar esa valía matemática de los grupos sociales de donde devienen los niños y niñas. Desde ese des-ligar, como reformar del pensamiento va a una re-ligar, que es una de las bases para conseguir emergentes educativos en la Educación Transcompleja. ¿Qué es re-ligar? “Re-ligar saberes implica re-significar para re-inventar” (FONTALVO, 2017, p.192).

"Re-ligar como práctica emergente debe incitar a otra forma de accionar y conformarse, en un ciudadano transmoderno, dialogante, no excluyente, consciente de su papel en la historia, especialmente la del Sur" (RODRÍGUEZ, 2019b, p.25). Es ir a una política liberadora de la opresión de la Educación Matemática, en este caso en los inicios de la educación, es ir a otro consentimiento en lo que significa educar en el papel planetario del ser humano, en los diálogos internos de aceptación en vez de desmitificación de su potencial.

Las comunidades donde viven los educandos son un medio potente para re-ligar su propio conocimiento de los juegos, identificando y viviendo la educación matemática en el habitad popular; esa acción comunitaria es provocativa, reaccionaria en la psique del niño y la niña porque atiende a procesos que él conoce, les motiva; se sienten útiles y complacidos que en su comunidad la matemática con su diversos conceptos y aportes les convive con sus vidas; es desde "el espacio público donde la política tiene sentido, allá se manifiesta el núcleo central de la presencia de los ciudadanos y en esos espacios donde se rechaza las tiranías que puede impulsar la sociedad política” (RODRÍGUEZ, 2020c, p.130).

Desde estas vertientes ruptura del adultocentrismo, docentecentrismo, escuelacentrismo, educar en la matemática es también "desarrollar la condición humana, luchar contra el egoísmo y la crueldad, comprometernos con la compasión y la solidaridad; es esa la función principal del ciudadano de estos tiempos; y en ello se debe converger en las instituciones educativas" (RODRÍGUEZ, 2019c, p.73). Si todavía no se ha comprendido que el ser humano no se educa en espacio físico; sino que la escuela debe promover un espacio 


\section{Revista (O) \\ Debates Insubmissos}

intersubjetivo de enseñanza y aprendizaje que está en su mente y que le acompaña para pensar la matemática desde cualquier vertiente en su vida; entonces no se ha desligado de la imposición adultocentrismo del docente. Estamos entonces estancados en la lucha del poder, en unas tecnologías del yo que apabullan y dominan al cuerpo; en la línea de investigación se propenden estos estudios en futuras publicaciones.

Ahora, bajo la conciencia clara de que todos podemos aprender, que en esos niños esta un potencia matemático inmenso que ya ha comenzado a desarrollarse en su afectividad comunitaria de los juegos; es de preguntarse por los métodos más adecuados para transmitir a los estudiantes el profundo interés y el entusiasmo que las matemáticas pueden generar: las respuestas: sus propios juegos y conocimientos previos que poseen, y que el docente debe bajarse de esa posición de sujeto que conoce e impone a sujeto que indaga en el discente lo que este conoce; para desde allí seguir el camino del conocer natural concreto del discente.

Ahora desligando lo que es la matemática ante la vida del docente y re-ligando la esencia de la verdadera matemática; él ahora con el corazón noble por el conocer día a día, por re-ligar su propia formación y práctica; debe saber divisar e ir a mostrar que la matemática constituye una herramienta esencial para la agudeza y manejo del entorno, y las experiencias que se expongan deberán corresponder con las que ellas y ellos han venido cimentando en su medio sociocultural. Antes de llegar a la institución educativa, las niñas y los niños ya han elaborado algunas nociones matemáticas que forman parte de su vida diaria, ya lo hemos venido comentando.

Con los juegos de los niños y niñas de su hogar y comunidad, de su entorno sociocultural se refuerza la concepción que gran parte de las matemáticas son juegos en el nivel inicial; así se pueden realizar métodos propios de la matemática, como recoger datos, experimentar, manipular, plantear conjeturas, inducir, deducir entre otras. Ahora, el docente no puede apresurarse a pensar que el niño y la niña no llegarán a los procesos de abstracción desde lo concreto. Desde luego que sí; es un asunto de maduración de las estructuras concretas y el deseo en la psique por ir más allá. 


\section{Revista \\ Debates Insubmissos}

Lo decolonial, la visión liberadora e inclusiva de los saberes matemáticos de las civilizaciones del Sur escasamente tratado en la Educación Matemática; que aquí incluimos con los saberes matemáticas de Occidentes, revalorizando a la matemática como Humanidad; y ahora en escena investigativa con la Educación Matemática Decolonial Transcompleja abre la posibilidad de re-ligar la Educación Matemática inicial modernistas e ir esencias maravillosas del conocimiento de las favelas, del Sur, de la etnomatemática (la matemática de los grupos sociales), ese dimensión política como es lo decolonial abre aventuras de la enseñanza de la matemática viva, consustanciada con "los procesos dialógicos de los discentes, con su cultura y vida cotidiana; abre el espectro de transposición didáctica de los saberes científicos de la matemática usando los saberes soterrados de ella" (RODRÍGUEZ, 2020c, p.132).

Nótese, que ahora una perspectiva por explorar es la matemática en la conformación del niño y de la niña; y del docente en primer lugar, la ciencia para la ciudadanía, para el desarrollo metacognitivo; en tal sentido la categoría diálogos dialógicos-dialécticos abre el espectro en lo dialéctico de poder desmotar en el dialogo afectivo y ameno con el niño desde su propia curiosidad lo que no está bien como esencia matemática; pero lo dialógico permite que ese reconocimiento no venga titulado como error castigador del adultocentrismo; sino que el error ante los ojos y comprensión de los actores de proceso educativo indica la persistencia del discente y la supervisión y revisión de la manera como el docente ha venido facilitando el aprender. La distinción clara que el docente enseña; pero que el discente aprende en su subjetividad y psique; allí hay una diferencia que se debe hacer cada vez más corta. Deseable que enseñar llegue a ser aprender; pero la toma de conciencia de esa supervisión y vigilancia es urgente.

Cuando en 1980, el matemático George Papy en su reforma de la enseñanza de la matemática en Argentina en entrevista que como afirme realizo Augusto Pérez afirmo que

\footnotetext{
Insistimos en crear situaciones gracias a las cuales el niño puede ejercer toda su capacidad de percepción. Queremos que se despierte en él la visión de todas las formas, para que a su vez desarrolle la capacidad de aprehensión de las cosas. Tratamos de logra una implicación múltiple del niño y los objetos, para que vea las cosas en distintos aspectos. Por eso es esencial también que el niño descubra los conceptos fundamentales en la experiencia común. Si no le enseñamos esto tal vez
} 
se atrofie una parte de su capacidad intelectual. Tenemos que usar el cerebro de la izquierda y el de la derecha" (PÉREZ, 1980, p.46).

Sin duda etas palabras, debemos llevarlas prendadas en nuestro corazón, el docente en la educación inicial no puede perder la oportunidad de formarse como verdadero docente liberador de la matemática para aprovechar la mejor oportunidad que tienen esos seres humano en su con-formación, en su madurez psíquica del niño, su paciencia y dedicación al respecto debe ser reveladora de un su condición humana y calidez, vocación para enseñar en influir de la mejor manera afectiva en esos seres humanos deseosos de ser tomados en cuentas. No sigamos con un adultocentrismo ignorante de su potencia, de su intervención en su propio aprender; ganaremos más siempre marcando positivamente una matemática armoniosa, alcanzable, motivadora y desarrolladora del ser, en la vida del niño y de la niña.

\section{RIZOMA CIERRE. EN UNAS REFLEXIONES FINALES DE APERTURAS}

En esta investigación bajo la transmodernidad se ha cumplido con el objetivo complejo de analizar el adultocentrismo en la Educación Matemática inicial en dos discursos en conflicto para la convivencia de los saberes matemáticos: los saberes de la cotidianidad del niño(a) y los saberes científicos impuestos en el aula; usamos deconstrucción rizomática como transmétodo. Todo enmarcado en la línea de investigación titulada: Educación Matemática Decolonial Transcompleja. Se han dado mesetas reconstructivas de los saberes; de la Educación Matemática Inicial como preeminencia en el ser humano y una reconstrucción urgente.

No son verdades acabadas, los rizomas no lo pretenden mostrar ni alcanzar, el transmétodo la deconstrucción decolonial pretende depravar en la herida; no para perpetuarla; sino para hacerla evidente y desgarradora en las consecuencias roturas de lo que podemos hacer en la educación inicial: sembrar esperanza, deseos, iluminar vidas y senderos de afectividad-cognitividad con la matemática o marcar vidas, oprimir personas, transmitir los males de la psique del viejo rechazo a la matemática. Los atenientes al proceso educativo debe tomar conciencia que está abierta en la imposición que comienza con el patriarcado; pero que haciendo daño con el adultocentrismo, la escuelacentrismo y el docentecentrismo. 
Tomemos ejemplos de grandes seres humanos docentes didactas de las matemáticas que han marcado positivamente vidas en los niños y niñas.

En una de las preguntas iniciales volvamos siempre ¿Cómo es posible este encuentro dialógico-dialéctico en la Educación Matemática? Hagamos realidad esa búsqueda en cada oportunidad, formemos para la libertad, hagamos de la ciencia matemática la más comprendida útil en la vida del niño y de la niña; representemos la vida matemáticamente ante la necesidad de re-civilizar la humanidad. El niño y la niña deben encendérsele una luz de amor y consideración; de fe en sí mismos, de apertura y crecimiento. Vamos hacerlo posible. El adultocentrismo ha muerto en cada línea de esta deconstrucción.

Una vez cumplido el objetivo complejo de investigación; en la conciencia de la instrucción al niño y a la niña, atendemos a la palabra de Dios siendo que "el temor del Señor es la instrucción de la sabiduría, y antes del honor viene la humildad" (Proverbios 15:33), pues "enséñame buen discernimiento y conocimiento, porque creo en tus mandamientos" (2 Salmo 119: 66). Padre amado que nos alumbras nuestras vidas danos tu sabiduría para hagamos realidad la principal tarea en la tierra: el servir; y cumplamos nuestro mandamiento rector: amarte por sobre todas las cosas; y amarnos de la misma manera que debemos amar a nuestro hermano.

\section{REFERENCIAS}

BELTRÁN-BARRERA, Yilson. La biocolonialidad: una genealogía decolonial. NÓMADAS, Bogotá, No 50, p.77-91, 2019.

CASTRO-GÓMEZ, Santiago. Michel Foucault y la colonialidad del Poder. Tabula Rasa, Bogotá, Universidad Colegio Mayor de Cundinamarca, No. 6, p. 153-172, 2007.

CASTRO-GÓMEZ, Santiago. Michel Foucault: Colonialismo y geopolítica. En: Ileana Rodríguez y Josebe Martínez. Estudios trasatlánticos coloniales: narrativas comando sistemas-mundo: colonialidad modernidad. Madrid, Anthropos, pp. 271-292, 2010. DELEUZE, Guille.; GUATTARI, Felix. Mille plateaux, Capitalisme et schizophrénie. Francia: Minuit, 1980.

DUARTE, Claudio. Sociedades adultocéntricas: sobre sus orígenes y reproducción. Revista Última Década, Valparaíso: CIDPA, № 36, p.99-125, 2012.

DUSSEL, Enrique. 1492. El encubrimiento del otro. Hacia el origen del mito de la 
modernidad. Madrid: Nueva Utopía, 1992.

DUSSEL, Enrique. Europa, modernidad y eurocentrismo. En: La colonialidad del saber: eurocentrismo y ciencias sociales. Perspectivas latinoamericanas. Buenos Aires:

CLACSO, Consejo Latinoamericano de Ciencias Sociales, 2000.

FIGUEROA-GRENETT, Claudio. ¿Ciudadanía de la niñez? hallazgos de investigación sobre el movimiento por una cultura de derechos de la niñez y adolescencia en Chile. Última Década, Valparaíso: CIDPA, Nº 45, p. 118-139, 2016.

FONTENLA, Martha. Diccionario de estudios de Género y Feminismos. Buenos Aires: Editorial Biblos.

FOUCAULT, Michel. El Orden Del Discurso. Barcelona: Fábula, 1990.

FOUCAULT, Michel. Microfísica del poder. Madrid: La Piqueta, 1992.

FOUCAULT, Michel. Vigilar y Castigar. Nacimiento de la prisión. Buenos Aires: Siglo XXI, 2002.

FOUCAULT, Michel. Tecnologías del yo y otros textos afines. Barcelona, Buenos Aires, México. Ediciones Paidós Ibérica, S.A. I.C.E. de la Universidad Autónoma de Barcelona, 2008.

FONTALVO, Rubén. Complejidad de la política, ciudadanía y políticas públicas. Justicia Juris, Bogotá, V. 7, N 1, p.46- 57, 2011.

FREIRE, Paulo; SHOR, Ira. Miedo y osadía: La cotidianeidad del docente que se arriesga a practicar una pedagogía transformadora. Buenos Aires: Siglo XXI, 1986.

FONTALVO, Rubén. Religar saberes y sentires para reinventar la convivencialidad. En:

Reinventando saberes para la intervención social. Ligia Muñoz de Rueda y Yolanda Rosa Morales Castro Compiladoras, (pp.173- 193). Barranquilla: Ediciones Universidad Simón Bolívar, 2017.

GONZÁLEZ, Andrés. El desencanto del pensamiento en Occidente un riesgo creciente de fragmentación. Madrid: IEEE. ES. Instituto Español de Estudios Estratégicos, 2017.

HIRA, Sandew. El largo recorrido de decolonizar la mente en Latinoamérica. Tabula Rasa, Cundinamarca, No 25, p.175-194, 2016.

LAY-LISBOA, Siu; MONTAÑÉS, Manuel. ¿Escuela Adultocéntrica, Contraadultocéntrica, Exoadultocéntrica, Academicista? La Infancia nos Habla de Relaciones Transformadoras en el Espacio Educativo. International Journal of Sociology of Education, Madrid, V.6, № 3, p. 323-349, 2017. Doi: 10.17583/rise.2017.2500

MARTÍNEZ, Irene. Construcción de una pedagogía feminista para una ciudadanía transformadora y contra-hegemónica. Foro de Educación, V.14, № 20, p129-151, 2016. Doi: 10.14516/fde.2016.014.020.008

MOGNOLO, Walter. El pensamiento decolonial: desprendimiento y apertura: un manifiesto. En: Santiago Castro-Gómez y Ramón Grosfoguel (eds.), 2007, El giro decolonial: 
reflexiones para una diversidad epistémica más allá del capitalismo global. Bogotá: Iesco/Pensar/Siglo del Hombre, 2007.

MORÍN, Edgar. Introducción al Pensamiento Complejo. París: Editorial Esfera, 2005.

MORÍN, Edgar; KERN, Annie. Tierra-patria. Buenos Aires: Nueva visión, 2006.

PANIKKAR, Raimón. The Intrareligious Dialogue. New York: Paulist Press, 1999.

PANIKKAR, Raimón. El diálogo indispensable: Paz entre las religiones. Barcelona:

Península, 2003.

PÉREZ, Augusto. Las matemáticas modernas: pedagogía, antropología y política. Entrevista a George Papy. Perfiles Educativos, Buenos Aires, Nº.10, p.41-46, 1980.

ORTIZ, Alexander ARIAS, María; PEDROZO, Zaida (2018). Pedagogía decolonial: hacia la configuración de biopraxis pedagógicas decolonizantes. Revista Ensayos Pedagógicos, Bogotá, V. XIII, N. 2, p.1-15, 2018.

RODRÍGUEZ, Milagros Elena. El poder que se practica, analizado desde Michel Foucault, en la enseñanza de la matemática. Praxis Educativa ReDIE, Durango, Nº. 7, p.7-24, 2013.

RODRÍGUEZ, Milagros Elena. Fundamentos epistemológicos de la relación patrimonio cultural, identidad y ciudadanía: hacia una educación patrimonial transcompleja en la ciudad. (Tesis de doctorado inédita). Universidad Latinoamericana y el Caribe, Caracas, Venezuela, 2017.

RODRÍGUEZ, Milagros Elena. Deconstrucción: un transmétodo rizomático transcomplejo en la transmodernidad. Sinergias educativas, Ecuador V.4, N², p.1-13, 2019a.

RODRÍGUEZ, Milagros Elena. Re-ligar como práctica emergente del pensamiento filosófico transmoderno. Revista Orinoco Pensamiento y Praxis, Ciudad Bolívar, V.7, No 11, pp.1335, 2019b.

RODRÍGUEZ, Milagros Elena. Criticidad, antropoética y complejidad en la cabeza bien puesta. Repensar la reforma. Repensar el pensamiento con Edgar Morín. Praxis Investigativa ReDIE, Durango V. 11, N² 20, p.60-74, 2019c.

RODRÍGUEZ, Milagros Elena. Visiones rizomáticas de la enseñanza de la matemática como decolonialidad. IE Revista de Investigación Educativa de la REDIECH, Chiguagua, $\mathbf{N}^{\mathbf{0}} 11$, e-836, p.1-17, 2020a. Doi: 10.33010/ie_rie_rediech.v11i0.836.

RODRÍGUEZ, Milagros Elena. La hermenéutica comprensiva, ecosófica y diatópica. Un transmétodo rizomático en la transmodernidad. Perspectivas Metodológicas, Buenos Aires, $\mathrm{N}^{\mathrm{o}} 19$, p.1-15, 2020b.

RODRÍGUEZ, Milagros Elena. La educación matemática decolonial transcompleja como antropolítica. Utopía y praxis latinoamericana, Maracaibo, 25, $\mathrm{N}^{\circ}$ EXTRA 4, 2020c, p. 125$137,2020 \mathrm{c}$.

SANTOS, Boaventura. Descolonizar el saber, reinventar el poder. Santiago de Chile: LOM, 2014. 
SERRANO, Cecilia. Educación y Entorno en la Infancia. Ingredientes Clave en el Desarrollo del Pensamiento Creativo. International Journal of Sociology of Education, Madrid, $\mathrm{N}^{\mathbf{o}} 1$, p.67-84, 2016. Doi: 10.17583/rise.2016.1896.

SKOVSMOSE, Ole. Investigación, práctica, incertidumbre y responsabilidad. En Valero, P. y Ole Skovsmose, O. Educación Matemática crítica. Una visión sociopolítica del aprendizaje y la enseñanza de las matemáticas (pp. 261-370). Colombia: Universidad de los Andes, Centro de Investigación y Formación en Educación, 2012.

VÁSQUEZ, Jorge. Adultocentrismo y juventud: Aproximaciones foucaulteanas. Revista Sophia: Colección de Filosofía de la Educación, Quito, N 15, p.217-234, 2013.

Submetido: $30 / 09 / 2020$

Aprovado: 21/03/2021 